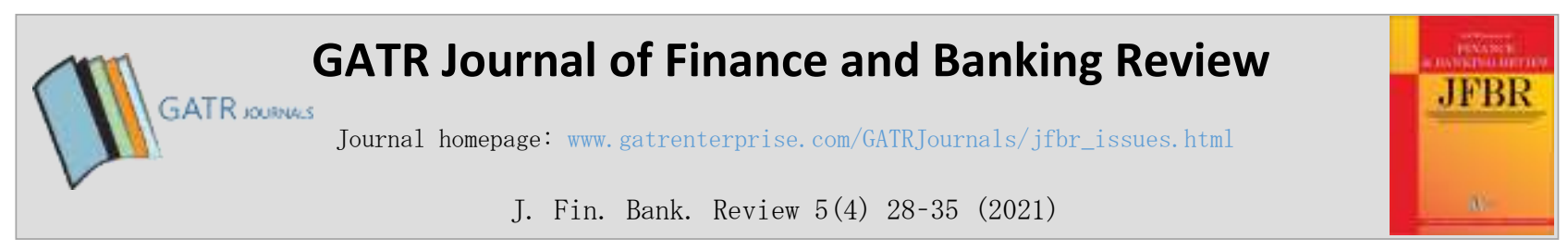

\title{
Benefits of Enterprise Risk Management: A Systematic Review of Literature
}

\author{
Sankalp Naik ${ }^{1}$ and Ch V V S N V Prasad ${ }^{2 *}$ \\ ${ }^{1,2}$ BITS Pilani K K Birla Campus, Zuarinagar, 403726, Goa, India
}

\begin{abstract}
Objective: In an enhanced climate of risk complexities, the firm's stakeholders desire a risk management framework that promises the benefits of efficiencies, transparencies, and solutions for interrelated risks. Enterprise risk management (ERM) is widely seen as a suitable instrument to address these issues. However, not all are convinced of ERM's benefits. This necessitates a review of extant literature and collating it to generate interrelated insights. This paper reviews articles on ERM from the management and finance domain and catalogs the benefits of ERM.

Methodology/Technique: This paper reviews 129 articles addressing ERM benefits. It examines the academic disciplines of journals publishing ERM studies by looking into their H Indices, SJR scores, and ABDC rankings to assess ERM's impact and acceptability among scholars. The research articles are analyzed for their subject domains, geographic scope, and methodology used in exploring the relationship between ERM adoption and its benefits to the firm. Collating and reviewing these articles enables the mitigation of data gaps. These studies were primarily from accounting, finance, management, corporate governance, and strategy domains.

Findings: Improved cost-effectiveness, earnings stability, increased profitability, improved decision making, better risk communication, competitive advantage, better resource allocation, enhanced firm value, and performance are the key benefits of ERM adoption identified in this study. A knowledge gap is presented around assessing ERM benefits and extending ERM research scope to developing countries like India.

Novelty: The study catalogs the benefits of ERM and makes a strong case for ERM adoption among firms.

Type of Paper: Review

JEL Classification: M10, M14, G30, G32

Keywords: Enterprise risk management (ERM); firm value; firm performance; ERM benefits; Covid19

Reference to this paper should be made as follows: Naik, S; Prasad, Ch.V.V.S.N.V. (2021). Benefits of Enterprise Risk Management: A Systematic Review of Literature, J. Fin. Bank. Review, 5 (4): $28 \quad-\quad 35$. https://doi.org/10.35609/jfbr.2021.5.4(3)
\end{abstract}

\section{Introduction}

As the COVID-19 pandemic of 2020 and the associated worldwide lockdowns took center stage, the business world had once again found itself in grave perils. Similarly, the global financial crisis (GFC) of 2007-09 had the business world riddled with uncertainty and clasping for the central bank's survival intervention. A significant highlight of GFC was the unique nature of the liquidity crisis that it triggered, which eventually manifested itself into an array of risks before finally culminating into a full-blown crisis (Mishkin, 2011).

\footnotetext{
* Paper Info: Revised: December 29, 2020

Accepted: March 31, 2021

* Corresponding author: Ch V V S N V Prasad

E-mail: prasad@goa.bits-pilani.ac.in

Affiliation: BITS Pilani K K Birla Campus, Zuarinagar, 403726, Goa, India
} 
It was a rare "black swan" - events characterized by shallow frequencies but severe outcomes (Aven, 2013). These events have enormous macroeconomic consequences and often issue no prior warnings, nor any of the current models are capable of envisaging such possibilities. Besides these events, frequent scams and scandals like Enron, Worldcom, Satyam, the Emission-gate, or Wirecard, continue barraging the financial world. These are not unavoidable minor infractions but a direct consequence of poor corporate governance. Failure of internal controls has also manifested into calamities. Firms are not just victims of rogue management or unforeseeable financial losses. Failure to incorporate changing technological trends can also drive a firm's products obsolete (Mellal, 2020). Indubitably, the nature of business risks has changed over the years. This has prompted stakeholders to explore and adopt new approaches to risk management that combine corporate governance, transparency, and strategic management (Pagach \& Wieczorek-Kosmala, 2020). Traditional methods of risk management were felt to be inadequate in dealing with the evolving nature of risks. The notion of enterprise risk management (ERM) first emerged in the 1990s when a wave of scandals and events such as the Barings Bank, Savings and Loans crisis, and the Indian stock market scandal rocked the financial world. These events had consequences that reverberated beyond their geographies (Arena et al., 2010). These inspired several publications on corporate governance reforms and legislations all over the world. They encouraged firms to move beyond the financial risks sphere and adopt a broader range of risks (Bledow et al., 2019). By the early 2000s, the notion of a "holistic" risk management framework took a more concrete shape. The core notion of ERM is to adopt a portfolio approach to managing risks (Khan et al., 2016). ERM promises to lower the firm's total risk by building resilience against systematic failures and monitoring growth opportunities (Al-Amri \& Davydov, 2016; Tekathen \& Dechow, 2013). Scholars argue that ERM would optimize performance and consequently increase a firm's value and longevity (Hoyt \& Liebenberg, 2011; Sprčić et al., 2015). Despite the widespread enthusiasm for ERM among stakeholders, the empirical evidence from academic research on the constitution and benefits of ERM remains inconclusive (Jankensgård, 2019; Power, 2009). Researchers note that the biggest obstacle in effective and efficient risk management is that it applies to future events that are impossible to predict (Jonek-Kowalska, 2019). ERM recognizes this limitation of risk management and focuses on building a risk culture capable of making more informed decisions in the face of uncertainty. However, the cynicism around the benefits of ERM continues. Many scholars and practitioners have criticized ERM as an unnecessary burden without any incremental benefits to the firm (Bromiley et al., 2015).

Motivated by the calls from research scholars to declutter the skepticism around ERM adoption and its benefits to the firm, this paper attempts to assess the literature evidence on ERM's effectiveness in managing enterprise risks and creating wealth. This article is a literature review paper that surveys the extant literature to catalog the studies concentrating on ERM benefits. The remainder of the paper is structured in the following way. Section two outlines the methodology adopted for the literature review undertaken for the study. Section three presents the literature review, and section four catalogs the benefits of ERM adoption. Section five discusses the implications of the findings and the final section concludes by addressing the limitations of the research and offers future research directions in ERM.

\section{Literature Review}

Traditional risk management (TRM) views risks as a complex web that needs to be simplified for effective management and treatment (Schiller \& Prpich, 2014). TRM endorsed that risks are function-specific and need to be managed in silos. However, the 1990s forced firms to consider the interdependencies among various risks. (Hoyt \& Liebenberg, 2011) argue that the segregation of risks leads to inefficiencies, and the approach is myopic and fails to incorporate the firm's strategic objectives. ERM emerged as the trifecta that aligns traditional risk management with the firms' strategic goals that take a comprehensive view of all risks faced by the firm (Kim, 2014). It proposes a portfolio approach to managing a firm's risks (Shad et al., 2019). ERM combines aspects of corporate governance and strategic management with risk management. Studies from (Hansen \& Andersen, 2014; Hoyt \& Liebenberg, 2011; Liebenberg \& Hoyt, 2003) confirm ERM's roles 
in value creation, risk reduction, performance enhancement, and strategic decision making. The Hydro One case study underscores ERM's role in strategic planning and capital budgeting (Mikes, 2008). However, all these studies are restricted to North America. Other researchers have criticized ERM as a management fad and noted that the research is centric to only the financial sector. Studies from (Arena et al., 2011; M. McShane, 2018; M. K. McShane et al., 2011; Mikes, 2009; Power, 2009) have found mixed to no evidence of ERM's role in delivering benefits to the firm. The criticism has only sharpened post-2007 when several firms boasting high standards of 'holistic' risk management failed during the GFC. Researchers have also pointed out endogeneity issues with ERM research (Bohnert et al., 2017, 2019). The notion of ERM's portfolio approach to risk management itself has been challenged on the grounds that a firm can only prioritize its risk but cannot achieve complete diversification of its risks (Bogodistov \& Wohlgemuth, 2017). Since endorsement by COSO in 2004 and ISO in 2009, the academic interest in ERM has grown sharply (. The primary subject areas of journals publishing articles on the benefits of ERM. Nearly $40 \%$ of the articles were from accounting and its allied finance and economics related journals. On the other hand, $26 \%$ of the articles were from journals focusing on management and associated domains like strategy, marketing, and HR. The H Indices of journals publishing the 127 studies under consideration ranged from 9 to 18 . The following paragraph describes the discipline, geographic scope, and industrial sectors of the articles under review.

Beyond the journal's primary subject areas, we conducted our separate analysis to note each of the article's subject domains. About $45 \%$ of the articles are from the finance and accounting domain. About $48 \%$ of the articles accounted for management and its allied areas like corporate governance and strategy. Previous literature surveys on ERM have highlighted the predominance of the US-based and financial sector-centric studies (Bromiley et al., 2015). In this review, the US accounts for a modest $27 \%$ of all research articles. Other sizeable contributions to ERM research are from Italy (8\%), Germany (6\%), China (6\%), and Australia (5\%). We found articles from at least 35 different countries. Research on ERM has expanded to Brazil, Columbia, UK, The Netherlands, Poland, Hungary, Sweden, Croatia, Palestine, Iran, Pakistan, South Korea, Malaysia, Singapore, and Taiwan. Financial sector - Banking and Insurance were the earliest adopters of ERM. It is a recurring sector in many of the articles surveyed in this paper. Most studies included in this review focus on listed companies consisting of diverse industrial sectors. Public sector undertakings (PSUs), oil, energy, manufacturing, and construction sectors are also quite popular among ERM researchers. Regulatory emphasis on adopting ERM by listed firms could be one reason for a large number of studies on listed firms. Recent articles also focus on the health and hospitality sectors confirming ERM's pan-industry popularity and acceptance as a good management practice.

\section{Research Methodology}

To fulfill the research objective, a structured literature review is necessary to appraise and collate all relevant empirical evidence to provide a complete interpretation of research results (Prasad et al., 2015; Prasad \& Prabhudesai, 2018). The articles chosen for this review are from ScienceDirect, Taylor \& Francis, Inderscience, and Emeraldinsights. These four databases are the largest repositories of high-quality peerreviewed journals. The keywords used to find articles were "Enterprise risk management", "ERM", "ERM and firm value", and "ERM and performance". Over 300 results were obtained, which were then trimmed down to articles specific to the study's research question, i.e., benefits associated with ERM adoption. Each of these articles was briefly analyzed. Finally, 127 research articles were selected based on their relevance to the research question. These articles were examined to note the journal's H Index, SCI score, ABDC ranking, and the article's number of citations. H Index and SCI score quantify a journal's scientific productivity and impact. The Australian Business Deans Council (ABDC) Journal Quality ranking assesses top journals relating to Business and Taxation Law; Economics; Finance including Actuarial Studies; Information Systems; Management, Commercial Services, and Transport and Logistics; Marketing and Tourism; and other areas. The journals were classified based on the Schimago subject area and category. 
The number of citations for each article was obtained from Google Scholar. The complete list was finalized by September 2020. In line with our research question, the articles were chosen if their objective were to assess the relationship between ERM adoption and firm performance or other benefits. The journals publishing these articles were cross-checked in the Scimago and ABDC list. Articles published in journals with an H Index verified in Scimago were selected. ABDC list was used to assess the quality of research. We began by examining the primary disciplines of journals publishing ERM studies. These articles were then scouted for their domain, geographical scope, industrial sectors, and methodologies employed. The next section addresses the benefits of ERM.

\section{Benefits of ERM}

One of the recurring criticism of ERM research has been the lack of contributions from management scholars (Bromiley et al., 2015; M. McShane, 2018). Besides, ERM's popularity among financial sector firms creates an impression that ERM is limited to the financial sector. To test the veracity of these presumptions, we divided the research articles into two categories - contributions by management scholars and contributions by finance and accounting scholars. The next sub-sections describe the findings from both of these categories.

\subsection{Benefits of Implementing ERM: Evidence from Management research}

Contrary to our expectations, $41 \%$ of the articles were from management scholars. Many of these studies highlight ERM's role in information dissemination and managerial decision making (Meidell \& Kaarbøe, 2017; Oliva, 2016; Wu et al., 2015). However, some studies note that not all firms were enthusiastic about ERM despite its implementation. Some studies suggest that managers saw it as an unnecessary regulatory burden or directive from the board (Arena et al., 2011). Many studies emphasized building a risk culture within the organization to enable communication channels and timely detection of threats. A common theme across many of the articles was using a formal risk management framework like COSO ERM/IF or ISO 31000. Despite ERM's holistic approach to risk management, its primary application was in the strategy setting. Some studies found that firms rated product obsolescence as the most critical threat. Hence, research and development (R\&D) emerged as an essential element of risk management. They also saw ERM as continuous, evolving, and agile (Tekathen \& Dechow, 2013). Many argued that effective communication reduced the overall enterprise risk and helped the firm achieve superior performance, not just financially but also in excellent customer feedback and brand loyalty. These studies viewed ERM as a resource. Most research conducted by management scholars were qualitative. Frequently mentioned management theories in qualitative studies were resource-based view, institutional theory, isomorphism, resource-dependent theory, actor-network theory, fads and fashion theory, and diffusion of innovation theory.

Management scholars emphasize nurturing risk management centric organizational culture and common language for risk communication. They see a decentralized approach to risk management to be more engaging and vigilant in identifying risks and potential future threats. (Mikes, 2008) notes ERM as an iterative but effective process to achieve company objectives. Risk scorecards, seminars, workshops, and training sessions emerged as popular tools used by firms to facilitate ERM awareness among employees. The goal of ERM is to reduce enterprise risk, which in turn would enhance performance. The analysis suggests that the ERM process and culture vary from firm to firm, but facilitating coordination among all departments of a firm remains the central theme (Jabbour \& Abdel-Kader, 2016). It can also be noted that the effectiveness of ERM adoption to deliver benefits is mediated by firm-specific characteristics like firm size, firm complexity, encouragement from the board, and the management's willingness to accommodate feedback (Saeidi et al., 2020; Sax \& Torp, 2015). Greater management consensus, competitive advantage, better resource allocation, improved decision-making, and improved investor confidence emerged as primary 
proxies for firm performance in these articles. An overwhelming majority of the articles in this approach used case studies. Other methodologies included phenomenological research, ethnographic research, and interviews with focus groups. Interviews and surveys were the primary tools of data collection.

\subsection{Benefits of Implementing ERM: Evidence from Accounting and Finance Research}

About $59 \%$ of the articles were by accounting and finance (A\&F) scholars. The relative share of publications from accounting and finance scholars in ERM has declined in recent years due to the surge in qualitative research by management scholars post-GFC. During GFC, quantitative models were severely criticized for underreporting risks (Mishkin, 2011). Nevertheless, the use of a quantitative approach is widespread among A\&F scholars. Accountants and auditors were the pioneers in ERM implementation. In many firms, the accounting and finance departments handle risk management. Utility theory, prospect theory, agency theory, stakeholder theory, and portfolio theory have shaped the A\&F research on ERM.

Many early studies on ERM by A\&F scholars used binary measures like the appointment of a Chief Risk Officer (CRO) or a Risk Management Committee's constitution as a proxy for ERM's presence (Liebenberg \& Hoyt, 2003; Lundqvist, 2015). However, recent studies use a more pragmatic scale that determines the level of ERM. This scale is constructed based on either primary or secondary data. Most secondary data based ERM scales use the COSO ERM/IF framework to measure ERM across strategy, compliance, reporting, and operations. The outcome of ERM is measured in terms of firm value or firm performance. Some studies distinguish the two as long-term and short-term outcomes, whereas others use the two terms interchangeably. Articles post-2009 advocate a more nuanced and less rigid approach to evaluate ERM in a firm setting. Most studies find a positive relationship between ERM adoption by a company and value creation and reduced enterprise risk. Most articles use Tobin's $Q$ to measure long-term value creation. Other benefits identified among these studies are lowered riskiness, improved performance, enhanced reputation, increased transparency, and boosted competitive advantage. Some studies show no association between ERM and value creation or accounting performance.

Interestingly, Some studies have shown a reduced performance with ERM (Otero González et al., 2020). Regression models are the most widely used methodologies. More than half of the studies using regression used the ordinary least square models. Other popular models include maximum likelihood, cox, generalized linear, probit, and poisson regression models. Structural equation modeling (SEM) models were popular with articles involving primary data. Data envelop analysis (DEA) and factor analysis were other recurring models. Most quantitative research articles used secondary data.

\section{Discussion}

This paper provides a comprehensive review of the benefits of implementing ERM in a firm. It takes into account both management and accounting \& finance perspectives on ERM. It debunks several gaps identified by ERM Scholars (Bromiley et al., 2015; Power, 2009). Firstly, ERM is not centric to just the US or North America, or the whole Western Hemisphere. Overtime is it has expanded geography. This study compiled research from at least 35 countries. A notable absentee in this list was India. Secondly, ERM is not restricted just to the financial sector. The concept of ERM materialized within the financial industry, and firms from the sector were the early adopters of a holistic approach to risk management owing to the high degree of regulation in the sector. However, ERM's benefits and transparency have propelled stakeholders from other sectors to direct their companies to adopt ERM, consequently expanding it to oil, natural gas, utilities, energy, manufacturing, construction, hospitality, healthcare, and even SMEs. It also debunks the notion that ERM is a fad and confirms it to be a trend. The other significant gap in the literature was the absence of contribution from management scholars. Our analysis reveals that there has been a considerable surge in research from management scholars over the last ten years. Contributions from management scholars have 
expanded ERM's epistemology and opened several new avenues for mixed-methodology approaches to measure ERM and gauge its impact on firm performance or value parameters.

\section{Conclusion}

One of the critical issues not addressed in this study was the measurement of ERM. It has certainly progressed from a binary measure based on the chief risk officer(CRO) appointment to a more pragmatic numerical scale based on the firm's ERM structure or proximity to a known ERM framework (e.g., COSO ERM/IF or ISO 31000). However, the ERM epistemology will gain from a hybrid of the two or a comprehensive measure based on a firm's industrial and environmental setting. The other critical issue ignored in this study is ERM's impact on intangible benefits such as goodwill, brand equity, and intellectual property. The resource-based view of ERM suggests ERM be an intangible asset of the firm. It is also a continuously evolving process costing both time and money. Despite the plethora of research in the last two decades, ERM research is still in its infancy and will benefit from expanding research in the above two areas. This review suggests that while ERM has expanded in geography, the world's fifth-largest economy with a domestic market capitalization of over $\$ 2$ Trillion, India remains a notable exception. As evident from the Google trends (trends.google.com), ERM has many interested parties in India. Post-COVID 19, risk management will become critical because of the global fiscal and monetary measures to revive the ailing economy. Stakeholder's push for a more sustainable culture of corporate governance will create momentum for implementing ERM. Research on India, South Asia, and other fast transforming developing countries like South Africa, Nigeria, Ghana, Angola, Brazil, and Mexico will be crucial to ERM epistemology. We suggest expanding the scope of ERM to these geographies. A prominent feature of this review is the inclusion of a large number of qualitative studies. Previously, qualitative analyses were noted as a research gap (Bromiley et al., 2015; Mikes, 2009; Power, 2004). However, the last decade has produced a large number of qualitative studies. Thus, we suggest a mixed methodology approach to measure ERM and its benefits for future studies. Research comprising both primary and secondary data will allow for a practitioner and academic collaboration on ERM. Thus, enriching the ERM learning curve.

\section{References}

Al-Amri, K., \& Davydov, Y. (2016). Testing the effectiveness of ERM: Evidence from operational losses. Journal of Economics and Business, 87, 70-82. https://doi.org/10.1016/j.jeconbus.2016.07.002

Arena, M., Arnaboldi, M., \& Azzone, G. (2010). The organizational dynamics of enterprise risk management. Accounting, Organizations and Society, 35(7), 659-675.https://doi.org/10.1016/j.aos.2010.07.003

Arena, M., Arnaboldi, M., \& Azzone, G. (2011). Is enterprise risk management real?. Journal of Risk Research, 14(7), 779-797.https://doi.org/10.1080/13669877.2011.571775

Aven, T. (2013). On the meaning of a black swan in a risk context. Safety science, 57, $44-51$. https://doi.org/10.1016/j.ssci.2013.01.016

Bledow, N., Sassen, R., \& Wei, S. O. S. (2019). Regulation of enterprise risk management: a comparative analysis of Australia, Germany and the USA. International Journal of Comparative Management, 2(2), 96-122. https://doi.org/10.1504/ijcm.2019.100856

Bogodistov, Y., \& Wohlgemuth, V. (2017). Enterprise risk management: a capability-based perspective. The Journal of Risk Finance. https://doi.org/10.1108/JRF-10-2016-0131

Bohnert, A., Gatzert, N., Hoyt, R. E., \& Lechner, P. (2017). The relationship between enterprise risk management, value and firm characteristics based on the literature. Zeitschrift für die gesamte Versicherungswissenschaft, 106(3), 311-324. https://doi.org/10.1007/s12297-017-0382-1

Bohnert, A., Gatzert, N., Hoyt, R. E., \& Lechner, P. (2019). The drivers and value of enterprise risk management: evidence from ERM ratings. The European Journal of Finance, 25(3), 234-255. https://doi.org/10.1080/1351847X.2018.1514314

Bromiley, P., McShane, M., Nair, A., \& Rustambekov, E. (2015). Enterprise risk management: Review, critique, and research directions. Long range planning, 48(4), 265-276.https://doi.org/10.1016/j.lrp.2014.07.005 
Hansen, A. Ø., \& Andersen, T. J. (2014). Exploring the Effect of Effective Risk Management Capabilities. In Contemporary Challenges in Risk Management (pp. 91-115). Palgrave Macmillan, London. https://doi.org/10.1057/9781137447623_5

Hoyt, R. E., \& Liebenberg, A. P. (2011). The value of enterprise risk management. Journal of risk and insurance, 78(4), 795-822.https://doi.org/10.1111/j.1539-6975.2011.01413.x

Jabbour, M., \& Abdel-Kader, M. (2016). ERM adoption in the insurance sector. Qualitative Research in Accounting \& Management. https://doi.org/10.1108/QRAM-03-2015-0035

Jankensgård, H. (2019). A theory of enterprise risk management. Corporate Governance: The International Journal of Business in Society. https://doi.org/10.1108/CG-02-2018-0092

Jonek-Kowalska, I. (2019). Efficiency of Enterprise Risk Management (ERM) systems. Comparative analysis in the fuel sector and energy sector on the basis of Central-European companies listed on the Warsaw Stock Exchange. Resources policy, 62, 405-415. https://doi.org/10.1016/j.resourpol.2019.04.011

Khan, M. J., Hussain, D., \& Mehmood, W. (2016). Why do firms adopt enterprise risk management (ERM)? Empirical evidence from France. Management Decision. https://doi.org/10.1108/MD-09-2015-0400

Kim, E. S. (2014). How did enterprise risk management first appear in the Korean public sector?. Journal of Risk Research, 17(2), 263-279. https://doi.org/10.1080/13669877.2013.808685

Liebenberg, A. P., \& Hoyt, R. E. (2003). The determinants of enterprise risk management: Evidence from the appointment of chief risk officers. Risk management and insurance review, 6(1), 37-52. https://doi.org/10.1111/10981616.00019

Lundqvist, S. A. (2015). Why firms implement risk governance-Stepping beyond traditional risk management to enterprise risk management. Journal of Accounting and Public Policy, 34(5), 441-466. https://doi.org/10.1016/j.jaccpubpol.2015.05.002

McShane, M. (2018). Enterprise risk management: history and a design science proposal. The Journal of Risk Finance. https://doi.org/10.1108/JRF-03-2017-0048

McShane, M. K., Nair, A., \& Rustambekov, E. (2011). Does enterprise risk management increase firm value?. Journal of Accounting, Auditing \& Finance, 26(4), 641-658. https://doi.org/10.1177/0148558X11409160

Meidell, A., \& Kaarbøe, K. (2017). How the enterprise risk management function influences decision-making in the organization-A field study of a large, global oil and gas company. The British Accounting Review, 49(1), 39-55. https://doi.org/10.1016/j.bar.2016.10.005

Mellal, M. A. (2020). Obsolescence-A review of the literature. Technology in Society, 63, 101347. https://doi.org/10.1016/j.techsoc.2020.101347

Mikes, A. (2008). Enterprise Risk Management at Hydro One. In Harvard Business School Cases (Vol. 44, Issue 0). Harvard Business School. http://search.ebscohost.com/login.aspx?direct=true\&db=bth\&AN=33775173\&site=ehostlive\%5Cnhttp://harvardbusinessonline.hbsp.harvard.edu/relay.jhtml?name=itemdetail\&id=109001

Mikes, A. (2009). Risk management and calculative cultures. Management Accounting Research, 20(1), 18-40. https://doi.org/https://doi.org/10.1016/j.mar.2008.10.005

Mishkin, F. S. (2011). Over the cliff: From the subprime to the global financial crisis. Journal of Economic Perspectives, 25(1), 49-70. https://doi.org/10.1257/jep.25.1.49

Oliva, F. L. (2016). A maturity model for enterprise risk management. International Journal of Production Economics, 173, 66-79. https://doi.org/10.1016/j.ijpe.2015.12.007

González, L. O., Santomil, P. D., \& Herrera, A. T. (2020). The effect of Enterprise Risk Management on the risk and the performance of Spanish listed companies. European Research on Management and Business Economics, 26(3), 111120. https://doi.org/https://doi.org/10.1016/j.iedeen.2020.08.002

Pagach, D., \& Wieczorek-Kosmala, M. (2020). The Challenges and Opportunities for ERM Post-COVID-19: Agendas for Future Research. Journal of Risk and Financial Management, 13(12), 323. https://doi.org/10.3390/jrfm13120323

Power, M. (2004). The risk management of everything. The Journal of Risk Finance. https://doi.org/10.1108/09657960410563540

Power, M. (2009). The risk management of nothing. Accounting, organizations and society, 34(6-7), 849-855. https://doi.org/https://doi.org/10.1016/j.aos.2009.06.001

Prasad, C. V., Lalitha, P., \& Srikar, P. V. N. (2015). Barriers to the use of information and communication technology (ICT) in secondary schools: Teacher's perspective. Journal of Management Research, 7(2), 190. DOI: https://doi.org/10.5296/jmr.v7i2.6935 
Prasad, C. V., \& Prabhudesai, R. (2018). An Empirical Study on TQM Practices and Its Influence on Employee Satisfaction and Performance in Technical Institutions: Teachers' Perspectives. J. Mgt. Mkt. Review, 3(3), 169-178.

Saeidi, P., Saeidi, S. P., Gutierrez, L., Streimikiene, D., Alrasheedi, M., Saeidi, S. P., \& Mardani, A. (2020). The influence of enterprise risk management on firm performance with the moderating effect of intellectual capital dimensions. Economic Research-Ekonomska Istraživanja, 1-30. https://doi.org/10.1080/1331677X.2020.1776140

Sax, J., \& Torp, S. S. (2015). Speak up! Enhancing risk performance with enterprise risk management, leadership style and employee voice. Management Decision. https://doi.org/10.1108/MD-10-2014-0625

Schiller, F., \& Prpich, G. (2014). Learning to organise risk management in organisations: what future for enterprise risk management?. Journal of Risk Research, 17(8), 999-1017.https://doi.org/10.1080/13669877.2013.841725

Shad, M. K., Lai, F. W., Fatt, C. L., Klemeš, J. J., \& Bokhari, A. (2019). Integrating sustainability reporting into enterprise risk management and its relationship with business performance: A conceptual framework. Journal of Cleaner production, 208, 415-425. https://doi.org/10.1016/j.jclepro.2018.10.120

Sprčić, D. M., Kožul, A., \& Pecina, E. (2015). State and perspectives of Enterprise risk management system development-the case of Croatian companies. Procedia Economics and Finance, 30, 768-779. https://doi.org/10.1016/S2212-5671(15)01326-X

Tekathen, M., \& Dechow, N. (2013). Enterprise risk management and continuous re-alignment in the pursuit of accountability: A German case. Management Accounting Research, 24(2), 100-121. https://doi.org/10.1016/j.mar.2013.04.005

Wu, D., Olson, D. L., \& Dolgui, A. (2015). Decision making in enterprise risk management: A review and introduction to special issue. Omega, 57, 1-4. https://doi.org/10.1016/j.omega.2015.04.011 